\title{
El principio de equidad tributaria en el tratamiento diferencial en el impuesto de renta entre sindicatos y sociedades
}

\author{
The principle of tax equity in the \\ differential treatment of income tax \\ between unions and societies
}

\section{O princípio da equidade tributária no tratamento diferenciado do imposto de renda entre sindicatos e sociedades}

\author{
Juan David Segura Medina*
}




\section{Resumen}

El presente artículo realiza un análisis de constitucionalidad conforme al principio de equidad tributaria aplicado al tratamiento tributario entre las sociedades comerciales y los sindicatos. Para dicho análisis se parte de la descripción legal de cada persona jurídica, se analiza el principio de equidad para, finalmente, realizar un estudio de caso, el cual hace una comparación efectiva, con juicios de valor conformes a los resultados obtenidos en la investigación.

Palabras clave: sindicatos; sociedades; principio; equidad; impuesto; renta; contrato; gremio; análisis.

\section{Abstract}

This article carries out an analysis of constitutionality in accordance with the principle of tax equity applied to tax treatment between commercial companies and unions. For this analysis, the legal description of each legal person is started; the principle of equity is analyzed to finally carry out a case study, which carries an effective comparison with value judgments in accordance with the results obtained in the investigation.

Key words: Unions; societies; principle; equity; tax; income; contract; union; analysis.

\section{Resumo}

Este artigo realiza uma análise da constitucionalidade de acordo com o princípio da equidade tributária aplicada ao tratamento tributário entre empresas comerciais e sindicatos. Para esta análise, é iniciada a descrição jurídica de cada pessoa coletiva, analisado o princípio da equidade para finalmente realizar um estudo de caso, que realiza uma comparação efetiva com os julgamentos de valor de acordo com os resultados obtidos na investigação.

Palavras-chave: Sindicatos; sociedades; princípio; equidade; impostos; renda; contrato; união; análise. 


\section{Introducción}

Hacia el siglo xx nace la Organización Internacional del Trabajo (оIт) y, con ella, la búsqueda de mejores garantías para los trabajadores. En 1948 se suscribe el Convenio 87, donde los Estados miembros proclaman la existencia de la libertad sindical y la protección del derecho de sindicación; a partir de este momento empieza a surgir un amplio desarrollo legal de los sindicatos en el mundo.

De acuerdo con lo anterior, los sindicatos surgen como una medida de protección y lucha de los trabajadores frente a los múltiples atropellos cometidos por su empleador. A pesar de esta premisa, esta organización no se limitó a la agrupación frente a un patrón en concreto, por el contrario, posibilitó la asociación sindical entre trabajadores de diversas empresas, o incluso entre trabajadores independientes de una misma rama u oficio.

Por tal razón, la asociación sindical no se restringe a la simple búsqueda de mejores garantías de unos trabajadores frente a su empleador, sino que permite una asociación amplia y fuerte donde es posible desarrollar actividades de diversa índole, las cuales compiten de manera directa con asociaciones de otra naturaleza como las sociedades comerciales.

La Carta colombiana no fue ajena a este fenómeno, dichas disposiciones de la orT fueron consagradas en la Constitución de 1991 a través del principio de autonomía sindical. En esta medida, la actividad sindical en nuestro país ha crecido de una manera significativa en los últimos años, con la adopción de formas sindicales que desarrollan actividades de prestación de servicios, actos de comercio e incluso desarrollo de actividades industriales, dicha posibilidad ha posicionado a los sindicatos como una buena opción a la hora de optar por un vehículo de participación en el mercado.

Entendido lo anterior, cobra vital importancia el estudio de un tema que se ha reducido a la investigación por parte del derecho laboral, desconociéndose su amplia importancia en temas tributarios, pues si entendemos que la libertad y autonomía sindical permiten la agrupación de individuos y la ejecución de diversas actividades que hacen parte de la oferta en el mercado, podremos señalar que los bienes y servicios no solo provienen de las tradicionales sociedades comerciales, sino de entes jurídicos sin ánimo de lucro que reciben ingresos, son partícipes, representan una competencia en el mercado y poseen un tratamiento diferencial.

Esta situación, más allá de enunciar una diferencia de condiciones legales e históricas, produce una diferenciación en el tratamiento tributario, porque los sindicatos en nuestro país son considerados como un no contribuyente del impuesto de renta, incluso en algunas jurisdicciones locales son exentos de ciertos tributos, mientras las sociedades comerciales tributan a una tarifa proporcional del $33 \%$.

Dicho aspecto nos lleva a reflexionar sobre la naturaleza de dicha diferenciación, y para ello he decidido traer a estudio el principio de equidad, como una guía para explorar las distintas consecuencias que otorga la norma tributaria a los sindicatos y a las sociedades comerciales cuando desarrollan actividades de prestación de servicios similares. 
En el presente trabajo se realizó la descripción de las personas jurídicas en comparación-sindicatos y sociedades comerciales-, lo que trajo a estudio el tratamiento en renta que otorga la ley tributaria para así, conforme al principio de equidad, realizar un estudio de caso donde se pueda hacer una comparación efectiva, estableciendo juicios de valor conforme a los resultados obtenidos.

Para el desarrollo de la investigación se tuvieron en cuenta múltiples fuentes legales y jurisprudenciales, doctrina oficial y de índole académica en lo referente al principio de equidad, los sindicatos, el impuesto de renta y la retención en la fuente.

\section{Aspectos dogmáticos}

\section{A. Definición conceptual y clasificación de los sindicatos}

El origen de la palabra sindicato proviene del latín syndicatus y esta, a su vez, de sindico, "defensor" (López, 2014, p. 458), y es quizás dicha significación el punto de partida más adecuado para comprender esta organización social, cuya finalidad inicial fue proteger los intereses de los trabajadores que sufrían graves atropellos por parte de su empleador.

La Real Academia Española define los sindicatos como la "Asociación de trabajadores constituida para la defensa y promoción de intereses profesionales, económicos o sociales de sus miembros" (s.f.), y reduce tal agrupación a empleados, lo que constituye un sentido amplio de la actividad sindical que no se limita a intereses frente a un empleador.

Existen diversas clases de sindicatos cuya composición trasciende esa pequeña relación trabajador-patrón, los sindicatos pueden ser de empresa, industria, gremio o de oficios varios. Para conocer de manera más amplia los conceptos abordados se sugiere consultar la premisa a partir de la cual se elabora el presente artículo (Segura y González, 2018).

\section{B. Contrato sindical y reglamento del contrato sindical}

El contrato sindical es la institución jurídica a través de la cual los sindicatos pueden participar en la promoción del trabajo colectivo, la prestación de servicios y ejecución de obras por parte de sus afiliados (Cerón y Camacho, 2015, p. 156), es una figura legal sui generis, que presenta características de contratos civiles, pero se rige por las normas propias del derecho colectivo del trabajo ${ }^{1}$. A la luz del artículo 482 del Código Sustantivo de Trabajo: "Se entiende por contrato sindical el que celebren uno o varios sindicatos de trabajadores con uno o varios empleadores o sindicatos patronales para la prestación de servicios o la ejecución de una obra por medio de sus afiliados"; por su parte, el artículo 1 del Decreto 1429 de 2010 señala las características de este contrato, calificándolo de 
solemne, nominado y principal, cuya ejecución se realiza con total autonomía administrativa, libertad sindical e independencia financiera.

La Corte Suprema de Justicia, en sentencia del 13 de diciembre de 1994, consideró que

... es claro que el contrato sindical tiene la naturaleza del contrato civil de prestación de servicios o de ejecución de obra o labor, porque siendo uno de los sujetos del negocio jurídico el sindicato y el otro el empresario, empleador o asociación de empleadores, pero sin que opere aquí la subordinación, la autonomía jurídica, propia del contrato civil, es la nota predominante en ese tipo de relación.

La normatividad en la materia ha otorgado un alto grado de importancia a este contrato, pues sugiere que ante la necesidad de un empleador o sindicato de empleadores se deberá evaluar en primera instancia la viabilidad de un contrato sindical ${ }^{2}$.

Por otro lado, el artículo 5 del Decreto 1429 de 2010, en desarrollo del Convenio 87 de la OIT, de 1948, ordena la elaboración de un reglamento por cada contrato sindical que ha de celebrarse, el cual debe de contener unas garantías mínimas como: el tiempo mínimo de afiliación de una persona para participar en la ejecución al igual que los derechos y las obligaciones de los afiliados; causales y procedimiento de retiro y de reemplazo de afiliados que participan en el desarrollo del contrato sindical; procedimiento para nombrar el coordinador del contrato sindical; la obligación del sindicato de administrar los temas concernientes al sistema de seguridad social integral, tales como afiliación, retiro, pagos y demás novedades ${ }^{3}$; procedimientos de selección de los afiliados; sistema disciplinario, $\mathrm{y}$, finalmente, el mecanismo de pagos referente a un sistema de compensación especial, esto es, la manera como se van a distribuir entre los afiliados los ingresos provenientes del contrato sindical.

Con referencia a estos aspectos, es claro que el reglamento del contrato sindical contiene las directrices que guiarán el desarrollo del contrato, expresando la gran autonomía que poseen estos entes jurídicos en la ejecución de una obra o prestación de un servicio.

Ahora bien, en lo que respecta a la relación que se surte en el desarrollo de un contrato sindical hay que señalar que existen tres tipos de relaciones; en primer lugar, hay un contrato de prestación de servicios ${ }^{4}$ entre el sindicato y el beneficiario del servicio u obra. La segunda es la relación entre el beneficiario de la obra ejecutada o de los servicios prestados y los afiliados o trabajadores sindicalizados (Cerón Coral y Camacho Ramírez, 2015, p. 156) y por último, aquella que nace entre el sindicato y sus propios afiliados o trabajadores sindicalizados, la cual no es laboral, sino que posee una naturaleza legal de afiliación; al respecto, la Corte Constitucional, en Sentencia T-457 de 2011, concluyó que 
... no existe el elemento esencial de la subordinación propio del contrato de trabajo. El afiliado partícipe durante la ejecución del contrato sindical compone el sindicato y se encuentra en un plano de igualdad con este frente a la distribución de los ingresos provenientes del contrato, al punto que recibe compensaciones y son sujetos de ciertas deducciones, las cuales para todos sus efectos se asimilan al concepto de salario, de acuerdo con lo definido en la asamblea de afiliados, en el reglamento y en el contrato sindical. Quiero ello decir que entre el sindicato y los afiliados partícipes no existe como tal una relación empleador-trabajador, pues si se viera desde la óptica contraria comprometería gravemente el derecho de sindicalización en Colombia. (art. 39 Superior)

Una vez estudiado el contrato sindical y su reglamento, podemos concluir que el primero es una figura única y exclusiva de las organizaciones sindicales, un instrumento legal que por excelencia permite la prestación de servicios y ejecución de obras a favor de terceros, y el segundo constituye la reglamentación legal del contrato sindical, donde se determinan las directrices que lo ciñen; estas figuras representan claramente el desarrollo de la libertad sindical, pues se encuentran permeadas de autonomía e independencia.

\section{Tratamiento tributario de las organizaciones sindicales}

Continuando con el análisis de las asociaciones sindicales, en seguida se describirá el régimen impositivo de los sindicatos.

Lo primero que hay que mencionar es que por expresa disposición del artículo 23 del Estatuto Tributario, los sindicatos no son contribuyentes del impuesto de renta, lo cual indica que tampoco lo son en CREE. Las organizaciones sindicales, como no contribuyentes de renta, de acuerdo con el literal B del artículo 369 del Estatuto Tributario (ET) no pueden ser objeto de retención, no obstante, deben actuar como agentes de retención en los pagos realizados a sus afiliados partícipes.

Al respecto, la Dirección de Impuestos y Aduanas Nacionales (DIAN), mediante Concepto 30490 de 2012, consideró que

... los Sindicatos como entidades no contribuyentes del impuesto sobre la renta y complementarios no son sujetos pasivos de retención en la fuente, es decir, no se les debe efectuar retención en la fuente; sin embargo, si intervienen en actos u operaciones por las cuales deban efectuar retención en la fuente, están obligados a realizarla y presentar la respectiva declaración de retención en la fuente por las retenciones que hayan realizado, como se indica en el último inciso de la norma transcrita y en tal sentido debe entenderse el Concepto 76999 de octubre 3 de 2011. Situación no aplicable a las personas naturales integrantes de la organización sindical. 
Tal concepto debe ser leído en concordancia con el Concepto 76999 del 2011, el cual indica:

La segunda es la forma en que intervienen los afiliados partícipes entre sí con el Sindicato en la ejecución del contrato sindical, para lo cual el reglamento deberá incluir lo pertinente a las compensaciones o participaciones y deducciones para los afiliados partícipes a que haya lugar, caso en el cual la retención en la fuente procederá por las compensaciones a pagar a los partícipes de acuerdo con lo aprobado en el Reglamento del Contrato Sindical. En consecuencia, la retención en la fuente y la tarifa aplicables por la compensación que reciben los trabajadores partícipes de un contrato sindical, dependerán del concepto en que sean percibidos de conformidad a lo que establezca el Reglamento del Contrato Sindical.

En consecuencia, se puede indicar que para efectos de la retención en la fuente aplicada al afiliado partícipe, es necesario tener en cuenta lo estipulado en el reglamento del contrato sindical, pues este identificará el concepto por medio del cual se recibe el pago, es decir, si constituye una compensación, una comisión o un honorario, pues sería dudoso indicar que dichos pagos son catalogados como salario, pues, como se ha expuesto en el presente escrito, es un contrasentido hablar de una relación laboral entre el sindicato y su afiliado.

Por otro lado, en lo que respecta al tratamiento del impuesto al valor agregado (IVA), serán contribuyentes siempre y cuando realicen algún hecho generador consagrado en el artículo 420 ET; como bien se pudo conocer, los sindicatos pueden desarrollar con limitaciones actividades comerciales e industriales; también por medio de la figura del contrato sindical pueden prestar servicios y ejecutar obras a favor de terceros, dichas actividades pueden encontrarse sujetas al IVA, por ello frente a este aspecto no existe ninguna condición especial para este tipo de asociaciones.

De acuerdo con la prestación de servicios a través del contrato sindical, la DIAN, en Concepto 78258 de 2010, señaló:

En consecuencia y por regla general, toda prestación de servicios en el territorio nacional se encuentra gravada con el impuesto sobre las ventas y únicamente se hallan excluidos los servicios expresamente señalados como tales en las respectivas disposiciones legales, motivo por el cual por el simple hecho de que el empresario contrate con la asociación sindical la prestación de servicios en el territorio nacional no convierte el servicio en excluido, es decir, la naturaleza de las partes contratantes no define la sujeción o aplicación del impuesto sobre las ventas, y mucho menos se puede afirmar que entre los contratantes exista un vínculo que cumple los requisitos legales para considerarse relación laboral.

Tal consideración de la administración tributaria no deja dudas sobre el tratamiento tributario del Iva de los sindicatos, máxime cuando en desarrollo de un contrato sindical entre 
el tercero y el sindicato media un contrato de prestación de servicios para todos los efectos tributarios según el Decreto 1372 de 1992 y el 420 del ET.

\section{Tratamiento tributario de las sociedades comerciales}

En desarrollo de la temática, es indispensable entrar a describir el tratamiento tributario en renta que reciben las sociedades comerciales en nuestro país.

En virtud del artículo 12 del ET, las sociedades y entidades son gravadas sobre sus rentas y ganancias ocasionales, tomando en consideración su condición de nacional o extranjera para efectos tributarios. La sociedad nacional tiene una tributación de renta mundial, mientras que la extranjera tiene una de renta en la fuente; la naturaleza de los ingresos tanto nacionales como extranjeros es descrita en los artículos 24 y 25 de la legislación tributaria.

La norma tributaria señala como contribuyentes del impuesto de renta a todas las sociedades y entes asimilados, sin hacer distinción alguna en su naturaleza, lo anterior se deduce de la redacción de los artículos 13 y 14 del ET.

Con respecto a las sociedades comerciales, se hace alusión a una clasificación de sociedades de capital y de personas, clasificación que finalmente indica el elemento predominante en la persona jurídica; de igual forma, dado el tipo societario, la responsabilidad del socio varía de manera importante; sin embargo, dicha clasificación en materia societaria, al igual que la responsabilidad del socio, no son relevantes en un aspecto tributario, pues la ley grava uniformemente todos los tipos de sociedad, incluso trata como tales a las sociedades de hecho, a pesar de ser ente sin personería jurídica de las cuales predica un ánimo de lucro.

Aunando a este último aspecto, se ha considerado que el ánimo de lucro es predicable cuando se distribuyen utilidades entre los asociados y no son reinvertidas en el objeto social (Piza et al., 2015, p. 275); conforme a lo anterior, el Decreto 4400 de 2004, al referirse a las entidades sin ánimo de lucro, considera que en ellas no hay ánimo de lucro cuando sus excedentes obtenidos en desarrollo de su actividad no se distribuyen en dinero o especie a los asociados de la entidad, ni siquiera en el momento de su retiro o liquidación de la persona jurídica; por el contrario, conforme el ánimo de lucro indica, podrá señalarse cuando haya distribución de utilidades, dándose la transferencia de dinero, bienes o derechos a favor de los asociados ${ }^{5}$.

Continuando con el estudio del impuesto de renta, el hecho generador del impuesto es todo ingreso susceptible de producir un incremento en el patrimonio que, para el caso en concreto, es recibido por una sociedad comercial o asimilada, dichos ingresos constituirán la base de la renta líquida, a la misma se le podrán realizar las correspondientes

Decreto Reglamentario 4400/2004, artículo 1, parágrafo 2. 
devoluciones, rebajas y descuentos, deducciones e imputación de costos, para obtener así la renta líquida gravable a la que finalmente se le aplicará la tarifa ${ }^{6}$.

La tarifa de renta para personas jurídicas bajo la legislación actual es del $33 \%{ }^{7}$, tarifa que por regla general es proporcional y fija. Debe indicarse que la actual reforma tributaria creó una sobretasa para el impuesto de renta y complementarios, aplicable a las personas jurídicas que para los años 2017 y 2018 tuvieran ingresos iguales o superiores a $\$ 800^{\prime} 000.000$ con una tarifa del 6 y del $4 \%$ respectivamente.

\section{RETENCIÓN EN LA FUENTE DE IMPUESTO DE RENTA}

Como mecanismo anticipado de recaudo de un impuesto, la retención en la fuente es plenamente aplicable al impuesto de renta y complementarios, desarrollada en virtud de las facultades otorgadas en el Decreto 1651 de 1961 y compilada en el libro segundo del ET.

$\mathrm{Al}$ respecto, el artículo 368 señala como agentes de retención a las personas jurídicas que por sus funciones intervengan en actos u operaciones en los cuales deben, por expresa disposición legal, efectuar la retención o percepción del tributo correspondiente. De esta manera, la regla general es la obligación de toda sociedad comercial de actuar como agente de retención cuando los supuestos de ley así lo exijan, lo cual conlleva una responsabilidad de retener, presentar la declaración mensual, consignar valores retenidos y expedir la respectiva certificación de las retenciones realizadas (Piza et al., 2015, p. 631).

En lo concerniente a la causación la DIAN, mediante Concepto 020295 del 8 de julio de 1991, consideró que

... la retención en la fuente debe efectuarse en el momento de pago o del abono en cuenta, el hecho que ocurra primero, entendiéndose por "pago" la prestación de lo que se debe y por "abono en cuenta", reconocimiento que se hace contablemente de una obligación para su posterior pago. En la retención en la fuente no puede el retenedor en forma discrecional tomar el momento en que se realice uno u otro de estos eventos, sino que debe efectuarla cuando se produzca el primero de ellos, según sea el sistema contable empleado o la modalidad de la operación.

Bajo esta enunciación, los principales conceptos sometidos a retención en la fuente por renta en una sociedad serán los pagos de rentas labores, dividendos y participaciones, honorarios, comisiones, servicios y arrendamientos, pagos al exterior, loterías, rifas, apuestas y similares, rendimientos, entre otros ingresos tributarios que sean considerados hechos generadores del impuesto de renta. 


\section{E. Principio de equidad tributaria}

El principio de equidad tributaria se encuentra consagrado en el artículo 363 de la Constitución, donde de manera concreta se indica que "el sistema tributario se funda en los principios de equidad, eficiencia y progresividad". Dicho principio es la concreción del tan conocido principio de igualdad, el cual al tomar una connotación tributaria es entendido como equidad.

Cuando se habla de igualdad en desarrollo del artículo 13 de la Constitución, nos referimos a ese tratamiento igualitario que debe brindar la ley al individuo, absteniéndose de crear tratos discriminatorios por razones de sexo, raza, origen nacional o familiar, lengua, religión, opinión política o filosófica. En este sentido, dicha naturaleza de la ley, al inscribirse en un ámbito económico y tributario, se sitúa como un límite al ejercicio del poder de normación, asignando al Estado la obligación de crear normas tributarias que midan la capacidad económica y la condición del individuo para imponerle una similar carga impositiva.

De acuerdo con lo anterior, la Corte Constitucional, en Sentencia C-183 de 1998 consideró:

El principio de equidad tributaria constituye un claro límite formal y material del poder tributario estatal y, por consiguiente, las reglas que en él se inspiran se orientan decididamente a poner coto a la arbitrariedad y la desmesura. No se trata de establecer igualdad aritmética. La tributación tiene que reparar en las diferencias de renta y riquezas existentes en la sociedad, de modo que el deber fiscal, expresión de la solidaridad social, tome en cuenta la capacidad contributiva de los sujetos y grupos y, conforme a ella, determine la carga fiscal, la que ha de asignar con criterios de progresividad, a fin de alcanzar grados cada vez mayores de redistribución del ingreso nacional.

Con respecto a esta posición, la Corte se refiere necesariamente a dos conceptos: capacidad económica y progresividad, el primero aparece en esta perspectiva señalando que frente a dos situaciones idénticas es menester otorgar el mismo tratamiento tributario. Sin embargo, en aras de lograr una igualdad real y efectiva, el sistema tributario está en la posibilidad de tratar de manera desigual situaciones que aparentemente merecerían el mismo tratamiento, exigencia que se concreta en el principio de progresividad (Piza et al., 2015, p. 148).

Atendiendo estas consideraciones, el principio de equidad como precisión tributaria de la igualdad tiene en cuenta los conceptos de capacidad económica del individuo y progresividad, en aras de buscar la igualdad real que, finalmente, se traduce en justicia tributaria. En este sentido, en el ordenamiento jurídico tributario deben existir leyes que otorguen iguales tratamientos a sujetos con similares condiciones, lo que implica que la norma general sea la uniformidad en el trato; sin embargo, se permite la existencia de preceptos 
que creen diferenciación si los mismos contienen una justificación constitucionalmente plausible, que puede obedecer a razones de equidad real o justicia contributiva.

En efecto, la Corte Constitucional, al abordar el estudio del presente principio, en diversos fallos ${ }^{8}$ ha considerado que debe tenerse en cuenta la razón objetiva del tratamiento, pues la equidad no es formal sino objetiva, bajo el entendido de que los tratamientos desiguales estarán permitidos siempre que con ellos se busque la igualdad material (Piza et al., 2015, p. 149).

La norma tributaria posee un carácter de generalidad, es decir que la naturaleza del hecho, acto o negocio que se grava se traduce a todos los sujetos que lo realizan, lo que implica que, en principio, estaría gravado todo sujeto que realice el hecho generador; no obstante, el legislador puede señalar que, dada la realización del hecho, acto o negocio, el mismo ocasione la obligación tributaria tomando en consideración la condición del individuo por razones de política fiscal o extrafiscal.

En la Sentencia C-183 de 1998, la Corte Constitucional señala:

La Corte no excluye que algunas exenciones o beneficios fiscales tengan una justificación atendible y puedan por lo tanto adoptarse. Lo que se quiere significar es que sólo pueden introducirse como instrumentos dirigidos a configurar materialmente la carga tributaria de manera técnica, justa y equitativa. Por el contrario, cuando la exención o beneficio fiscal, no tiene razón de ser distinta de la mera acepción de personas, ella se presenta contraria a la generalidad del tributo y, frente a los obligados que se encuentran en la misma relación con el hecho imponible, como clara afrenta al principio de igualdad en la carga tributaria.

En este sentido, el principio de equidad puede resumirse en un límite al ejercicio del poder tributario, que bajo la concepción aristotélica busca que la norma tributaria conceda tratamientos iguales a los iguales y desiguales a los desiguales con una finalidad de igualdad real y efectiva.

Sin embargo, dada esta concepción, será necesario describir los distintos criterios que debe tener en cuenta el legislador a la hora de establecer tratamientos disimiles, pues estos podrían resultar inconstitucionales al crear desigualdad.

De acuerdo con lo anterior, la Corte ha establecido diversos test de proporcionalidad que son convenientes a la hora de evaluar la inconstitucionalidad de una norma; de esta manera, se ha referido especialmente a un test liviano, intermedio y fuerte.

Frente a estos criterios, la Corte Constitucional, en Sentencia C-183 de 1998, considero lo siguiente:

8 Corte Constitucional, sentencias: C-221 de 1992; C-094 de 1993; C-010, C-222 y C-489 del 1995; C-036, C-393 y C-412 de 1996; C-296 y 215 de 1999; C-1376 de 2000; C-508 y C-861 de 2006; C-903, C-822, C-635, C-913 y C-397 de 2011; C-1021 y C-304 de 2012 y C-197, C-264 y C-249 de 2013. 
Si del análisis preliminar de una ley tributaria surge un indicio de inequidad o arbitrariedad, derivado de un reparto desigual de la carga tributaria, el examen de constitucionalidad no podrá ser débil. La exacción fiscal normalmente significa un detrimento patrimonial y una mengua de la libertad que, sin embargo, deben soportar las personas a título de deber constitucional y legal. Por esta razón, ya que esta suerte de restricciones o reducciones son connaturales a las leyes impositivas, salvo que las regulaciones sean en sí mismas manifiestamente irrazonables o desproporcionadas, no cabe por esta circunstancia predicar su inconstitucionalidad. La situación es diferente cuando la ley, prima facie, afecta un derecho o garantía constitucionales más allá de lo que pueda históricamente considerarse como efecto normal de la medida tributaria, hasta el punto de que sea posible afirmar que existe un indicio de inequidad o arbitrariedad. En este caso, se torna necesario ensayar un test intermedio que, si bien no comprende el estudio de la proporcionalidad estricta de la norma, sí incluye el examen de las razones que la avalan, de modo que la misma será constitucional siempre que se identifique un motivo suficiente para haberla expedido y que permita desvirtuar el señalado indicio.

Conforme a lo anterior, en igual providencia considera:

Toda subvención, exoneración o beneficio fiscal, en cuanto abarca sólo a un grupo de contribuyentes actuales o potenciales, en cierta medida afecta el principio de igualdad, el cual representa el más importante límite del poder tributario estatal. Sin embargo, la afectación de la igualdad traspasa el umbral de la normalidad cuando dicha subvención, exoneración o beneficio se niega a un contribuyente que se encuentra en la misma situación formal que la de los destinatarios de la norma favorable. Aquí puede aludirse a un indicio de trato discriminatorio.

De acuerdo con esta postura, el test intermedio debe aplicarse cuando exista un indicio de trato discriminatorio, pues el presupuesto de la norma otorga un beneficio a un sujeto y excluye a otro que ostenta su misma condición formal. Percibido dicho indicio, la Corte debe analizar si la exclusión obedece a una razón fundamentada.

De igual forma, el test liviano o débil será procedente solo cuando no exista un indicio de inequidad o arbitrariedad, y será fuerte, según la Corte, cuando la aplicabilidad de dicho criterio sea manifiestamente desproporcionada. Al revisar el caso en concreto indicó que "no se apela al test fuerte, puesto que la irrazonabilidad o desproporcionalidad del trato no es manifiesta, sino que figura a nivel de mero indicio".

\section{Análisis de casos}

La presente sección tiene como objetivo presentar, comparar y analizar dos casos en concreto, en los cuales se presenta el desarrollo de actividades similares por parte de sindicatos de gremio y de sociedades por acciones simplificadas (S.A.S.), para ello se hará una 
breve descripción del caso, adjuntando un conjunto de cuadros explicativos que tienen como finalidad exponer en detalle las operaciones que se dan al interior de estas asociaciones cuando interactúan con terceros en el cumplimiento de un contrato; en dichas operaciones se explicarán los ingresos y egresos, haciendo alusión específicamente al cumplimiento de obligaciones legales de índole laboral y tributaria; dadas estas descripciones se procederá a realizar un análisis de las situaciones expuestas teniendo en cuenta diversos aspectos referentes al régimen legal aplicable, impuesto de renta, retención en la fuente por impuesto de renta y flujo de caja.

\section{A. Caso I-Sindicato de gremio}

SALUD X es un sindicato de gremio conformado por profesionales, especialistas y personal que ejerce oficios de la salud (médicos, enfermeras, instrumentadores quirúrgicos, entre otros). El objeto social de este sindicato, conformado por 25 profesionales de la salud, es el desarrollo de procesos y subprocesos afines, conexos o complementarios en el sector salud, en concordancia con el perfil de los afiliados del sindicato.

SALUD X celebra diversos contratos sindicales en los cuales se obliga al desarrollo de procesos de salud, prestando a través de sus afiliados partícipes los servicios de salud correspondientes al área de urgencias de una empresa social del Estado (ESE). En el apartado anterior se realizó una breve descripción del contrato sindical, reconociéndolo como el instrumento jurídico sui generis que por excelencia celebra el sindicato a la hora de prestar un servicio o realizar una obra a favor de un tercero; de igual forma, se definió la figura del reglamento del contrato sindical como un elemento que define, precisa y concreta el desarrollo del contrato sindical, situación que lleva a definir el régimen de pagos, su modalidad, la proporción, el régimen disciplinario, los beneficios sindicales, entre otros.

En el presente caso SALUD X, sindicato de gremio, celebra el contrato sindical 001 con la ESE Hospital San Antonio del municipio de Zipaquirá (Cundinamarca), cuyo valor asciende a la suma de \$150`000.000, con una duración de un mes; su objeto es la prestación de servicios de salud a través de sus 25 afiliados en el proceso de urgencias, con los cuales se suscribe un convenio de ejecución.

Según el reglamento del contrato 001 , el sindicato ha determinado que cada afiliado partícipe recibirá como compensación por sus 100 horas prestadas en desarrollo del proceso contratado, la suma de $\$ 5^{\prime} 000.000$. De acuerdo con el régimen legal de los afiliados que participan en este contrato, el pago de la seguridad social se realiza como un independiente agremiado, pues, como se explicó en el apartado anterior, no existe relación laboral entre la persona jurídica sindicato y el afiliado, es decir que el pago se realiza conforme a la planilla tipo Y, tomando como ingreso base de cotización (IBC) el $40 \%$ de lo devengado, valor que según el sistema de compensaciones estipulado y los estatutos sindicales, será deducido previo al pago.

De acuerdo con lo anterior, por concepto de seguridad social (salud y pensión) cada afiliado partícipe realiza un aporte de $\$ 570.000$, el cual es deducido previamente por el 
sindicato, valor que resulta de aplicar el $16 \%$ (por concepto de pensión) y $12,5 \%$ (por concepto de salud).

Conforme al reglamento del contrato sindical, se realizan unos pagos correspondientes a seguridad social por los 25 afiliados partícipes por un valor de $\$ 14.250 .000$, costos administrativos del contrato por $\$ 7.500 .000 \mathrm{y}$, finalmente, un pago por concepto de compensaciones de sus 25 afiliados por un valor de $\$ 110.750 .000$.

Dicha información se encuentra resumida en la tabla 1:

Tabla 1. Contrato Sindical 001- Egresos E ingresos

\begin{tabular}{|l|c|}
\hline \multicolumn{1}{|c|}{ Contrato sindical 001 } & Valor \\
\hline INGRESOS OPERACIONALES & $\$ 150.000 .000$ \\
\hline Pago compensaciones & $\$ 110.750 .000$ \\
\hline Pago seguridad social (salud, pensión) & $\$ 14.250 .000$ \\
\hline Pago costos administrativos del contrato & $\$ 7.500 .000$ \\
\hline Impuesto de renta & 0 \\
\hline Total & $\$ 17.500 .000$ \\
\hline
\end{tabular}

Fuente: elaboración propia.

La tabla 1 consigna el ingreso mensual recibido por SALUD X atribuible al contrato sindical 001, también los principales egresos, sobre todo de índole operacional, como los costos administrativos del contrato (gerencia, empleados, abogado y contador), la contraprestación de sus afiliados y los pagos correspondientes a la seguridad social. En tal supuesto el sindicato deja el excedente para reinvertirlo en el objeto social.

Frente al tema tributario, el sindicato, al ser un declarante no contribuyente ${ }^{9}$, no es un sujeto pasivo del impuesto de renta, razón por la cual no se hace alusión a gastos atribuibles a este tributo, mucho menos la entidad contratante puede realizarle retención en la fuente por este concepto.

En lo que respecta a la contraprestación recibida por los afiliados partícipes según el régimen de compensaciones, la suma individual asciende a \$4.430.000, por ello SALUD $\mathrm{X}$ realiza la retención en la fuente a sus afiliados partícipes, tomando como base gravable el valor neto recibido, sin excluir las sumas por concepto de salud y pensión, pues, estas fueron deducidas por el sindicato previo al pago; para el supuesto no consideramos la existencia de deducciones, pero sí el $25 \%$ de renta exenta, como se explica en la tabla 2.

Tabla 2. Contrato sindical. Retención, ingresos no CONSTITUTIVOS DE RENTA, DEDUCCIONES Y RENTAS EXENTAS

\begin{tabular}{|l|c|}
\hline \multicolumn{2}{|c|}{ Retención en la fuente } \\
\hline UVT 2017 & $\$ 31.859$ \\
\hline
\end{tabular}




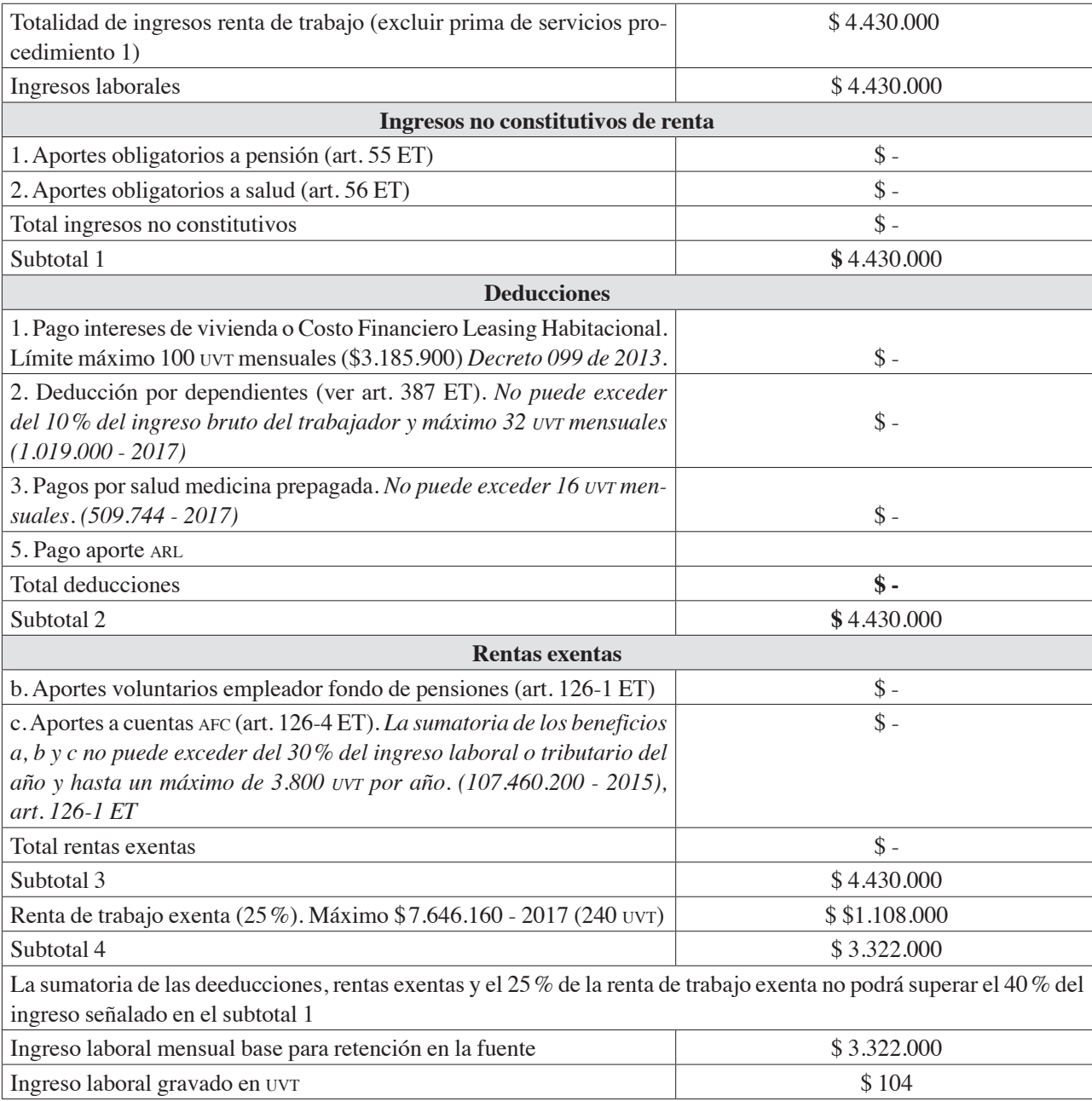

Fuente: elaboración propia.

Tabla 3. Retención en la fuente a título de Renta

\begin{tabular}{|c|c|c|c|}
\hline Hasta & $\begin{array}{c}\text { Tarifa } \\
\text { marginal }(\%)\end{array}$ & Impuesto & $\begin{array}{c}\text { Retención por } \\
\text { aplicar }\end{array}$ \\
\hline & & & \\
\hline 95 & 0 & $\$ 0$ & - \\
\hline 150 & 19 & $\begin{array}{l}\text { (Ingreso laboral gravado expresado en UVT menos } \\
95 \text { UVT)*19\% }\end{array}$ & $\$ 56.000$ \\
\hline 360 & 28 & $\begin{array}{l}\text { (Ingreso laboral gravado expresado en uVT menos } \\
150 \text { UVT)*28\% más } 10 \text { UVT }\end{array}$ & - \\
\hline En adelante & 33 & $\begin{array}{l}\text { (Ingreso laboral gravado expresado en uvT menos } \\
360 \text { uVT)*33\% más } 69 \text { uVT }\end{array}$ & - \\
\hline
\end{tabular}




\begin{tabular}{|l|c|}
\hline UVT 2017 & $\$ 31.859$ \\
\hline $\begin{array}{l}\text { Ingreso laboral gravado } \\
\text { en UVT }\end{array}$ & 104 \\
\hline \multicolumn{2}{|c|}{$\$ 56.000$} \\
\hline
\end{tabular}

Fuente: elaboración propia.

Una vez aplicado el proceso de depuración al afiliado se le realiza una retención en la fuente a título de renta de $\$ 56.000$.

Cabe indicar que, en virtud de la libertad sindical, puede establecerse un sistema de beneficios anuales, provisiones a las que se hizo referencia en el apartado anterior; para ello, al afiliado partícipe se le descuenta un porcentaje de su pago para provisionar lo referente a vacaciones, cesantías, interés a la cesantía y prima de servicios. En el presente caso no se hará referencia a estas provisiones.

\section{B. Caso II - Sociedad comercial régimen tributario ordinario}

SALUD Y SAS es una sociedad comercial que emplea profesionales de la salud con el objetivo de suplir necesidades de terceros, su objeto social es el desarrollo de procesos y subprocesos afines, conexos o complementarios en el sector salud. Dicha entidad celebra contratos de prestación de servicios en los cuales se obliga al desarrollo de procesos de salud, prestando tal servicio a través de sus contratistas, que son independientes, vinculados por contrato de prestación de servicios.

En el presente caso cabe la posibilidad de desarrollar la labor a través de un contrato de prestación de servicios suscrito entre la SAS y la ESE, donde participan los contratistas de la sociedad comercial, como prestadores de servicios en desarrollo de un proceso misional. Sin embargo, dicha prestación de servicios también podría desarrollarse por personal vinculado mediante contrato de trabajo, en el supuesto de que los mismos fueran profesionales de la salud, sin embargo, por temas de costos no es viable realizar dicha contratación, pues la vinculación laboral supone altos costos por cuenta de prestaciones sociales, aportes del empleador de seguridad social, entre otros. Debido a esta situación, no se planteará el caso con personal vinculado mediante contrato laboral.

SALUD Y SAS celebra el contrato de prestación de servicios 001 con la ESE Hospital San Antonio del municipio de Zipaquirá (Cundinamarca), cuyo valor asciende a la suma de $\$ 150^{\prime} 000.000$, con una duración de un mes; su objeto es la prestación de servicios de salud a través de sus 25 contratistas.

Previamente, la sociedad tiene vinculados a sus 25 contratistas con unos honorarios de $\$ 5.000 .000$, la afiliación de cada uno de ellos será como independiente, tomando como IBC el $40 \%$ de lo devengado, mediante planilla tipo I, aplicando a esta base $12 \%$ salud y $16 \%$ pensión.

Conforme a lo anterior, la sociedad pagará por concepto de honorarios $\$ 125.000 .000$ y unos costos administrativos de $\$ 7^{\prime} 500.000$ (tabla 4). 
El principio de equidad tributaria en el tratamiento diferencial en el impuesto de renta entre sindicatos y sociedades 23

Tabla 4. Contrato PREstación de SERvicios 001- Egresos E INGResos

\begin{tabular}{|l|c|}
\hline \multicolumn{1}{|c|}{ Contrato prestación de servicios 001 } & Valor \\
\hline INGRESOS OPERACIONALES & $\$ 150.000 .000$ \\
\hline Retención en la fuente & $\$ 16.500 .000$ \\
\hline Pago honorarios & $\$ 125.000 .000$ \\
\hline Pago costos administrativos del contrato & $\$ 7.500 .000$ \\
\hline Total & $\$ 1.000 .000$ \\
\hline
\end{tabular}

Fuente: elaboración propia.

Con respecto a las obligaciones tributarias, a SALUD Y SAS se le realiza retención en la fuente pues es un sujeto pasivo del impuesto de renta, aplicando la tarifa del $11 \%$ por concepto de honorarios, retención en la fuente por \$16'500.000.

Bajo el mismo concepto, la entidad comercial deberá pagar los honorarios convenidos a cada profesional de la salud, tomando como base inicial los $\$ 5^{\prime} 000.000$, depurando de esta base $\$ 1.025 .000$ correspondientes a seguridad social; para el supuesto no consideramos la existencia de deducciones, pero sí el $25 \%$ de renta exenta, como se explica en la tabla 5.

\section{Tabla 5. Contrato PRESTACión de SERVICIOS. RETENCión, INGRESOS} NO CONSTITUTIVOS DE RENTA, DEDUCCIONES Y RENTAS EXENTAS

\begin{tabular}{|c|c|}
\hline \multicolumn{2}{|l|}{ Retención salarios } \\
\hline Totalidad de ingresos renta de trabajo (excluir prima de servicios procedimiento 1 ) & $\$ 5.000 .000$ \\
\hline Ingresos laborales & $\$ 5.000 .000$ \\
\hline \multicolumn{2}{|l|}{ Ingresos no constitutivos de renta } \\
\hline 1. Aportes obligatorios a pensión (art. 55 ET) & $\$ 320.000$ \\
\hline 2. Aportes obligatorios a salud (art. 56 ET) & $\$ 250.000$ \\
\hline Total ingresos no constitutivos & $\$ 570.000$ \\
\hline Subtotal 1 & $\$ 4.430 .000$ \\
\hline \multicolumn{2}{|l|}{ Deducciones } \\
\hline $\begin{array}{l}\text { 1. Pago intereses de vivienda o Costo Financiero Leasing Habitacional. Límite máximo } 100 \text { uvT } \\
\text { mensuales }(\$ 3.185 .900) \text {. Decreto } 099 \text { de } 2013 \text {. }\end{array}$ & N/A \\
\hline $\begin{array}{l}\text { 2. Deducción por dependientes (ver art. } 387 \mathrm{ET}) \text {. No puede exceder del } 10 \% \text { del ingreso bruto } \\
\text { del trabajador y máximo } 32 \text { uvT mensuales }(\$ 1.019 .000-2017)\end{array}$ & N/A \\
\hline 3. Pagos por salud medicina prepagada. No puede Exceder 16 uvT mensuales ( $\$ 509.744$ - 2017) & N/A \\
\hline 5. Pago aporte ARL & N/A \\
\hline Total deducciones & $\mathrm{N} / \mathrm{A}$ \\
\hline Subtotal 2 & $\$ 4.430 .000$ \\
\hline \multicolumn{2}{|l|}{ Rentas exentas } \\
\hline b. Aportes voluntarios empleador Fondo de Pensiones (art. 126-1 ET) & $\mathrm{N} / \mathrm{A}$ \\
\hline $\begin{array}{l}\text { c. Aportes a cuentas AFC (art. } 126 \text { - } 4 \text { ET). La Sumatoria de los beneficios a, b y c, no pueden ex- } \\
\text { ceder del } 30 \% \text { del ingreso laboral o tributario del año y hasta un máximo de } 3.800 \text { UVT por año. } \\
(107.460 .200 \text { año 2015), art. 126-1 ET }\end{array}$ & N/A \\
\hline Total rentas exentas & N/A \\
\hline Subtotal 3 & $\$ 4.430 .000$ \\
\hline
\end{tabular}




\begin{tabular}{|l|c|}
\hline Renta de trabajo exenta (25\%). Máximo \$7.646.160 - 2017 (240 UVT) & $\$ 1.108 .000$ \\
\hline Subtotal 4 & $\$ 3.322 .000$ \\
\hline $\begin{array}{l}\text { La sumatoria de las deducciones, rentas exentas y el 25\% de la renta de trabajo exenta no podrá superar el } 40 \% \text { del } \\
\text { ingreso señalado en el subtotal 1 }\end{array}$ & $\$ 3.322 .000$ \\
\hline Ingreso laboral mensual base para retención en la fuente & 104 \\
\hline Ingreso laboral gravado en uvT &
\end{tabular}

Fuente: elaboración propia.

Tabla 6. Retención EN La fuente a título de Renta

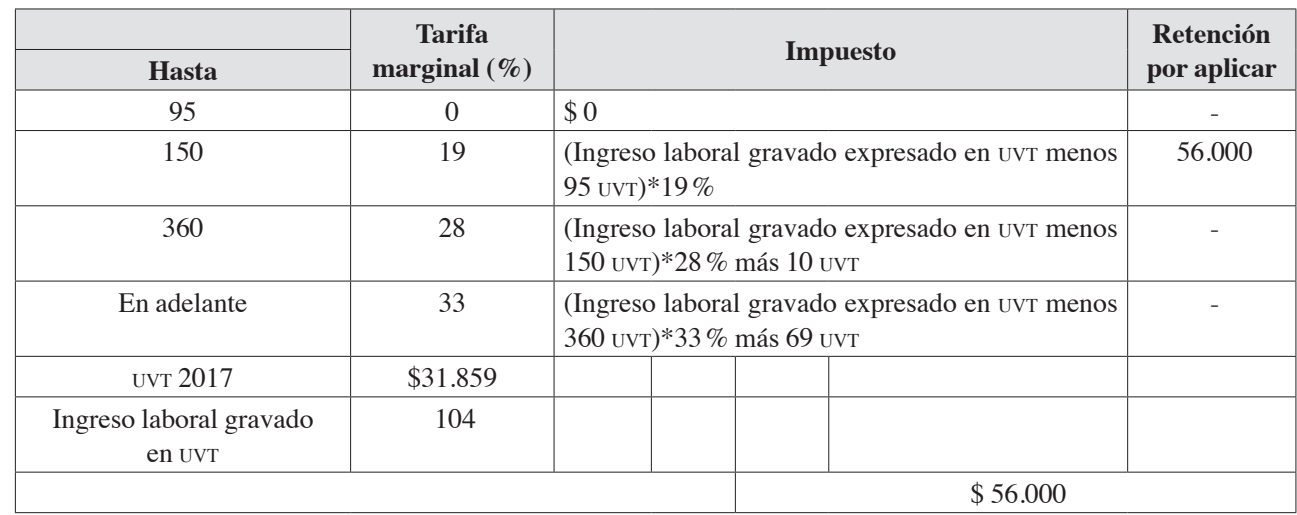

Fuente: elaboración propia.

La anterior retención en la fuente realizada al momento del pago a sus contratistas es de $\$ 56.000$.

Ahora, al realizar el análisis del impuesto de renta, la sociedad SALUD Y SAS es un contribuyente del impuesto de renta a una tarifa del $33 \%{ }^{10}$, cuya base gravable estará compuesta por el ingreso recibido del contrato 001, pues, es considerado de fuente nacional según el artículo 24 del ET; para el cálculo del impuesto tenemos la siguiente operación (tabla 7):

\section{TABla 7. IMPUESTO A LA RENTA}

\begin{tabular}{|l|l|r|}
\hline & \multicolumn{1}{|c|}{ Renta } & \\
\hline & Ingresos ordinarios & $\$ 150.000 .000$ \\
\hline$(-)$ & $\begin{array}{l}\text { Deducción expensas necesarias costos administrativos del con- } \\
\text { trato (art. 107) }\end{array}$ & $\$ 7.500 .000$ \\
\hline$(-)$ & Deducción honorarios (art. 114) & $\$ 125.000 .000$ \\
\hline$(-)$ & Renta líquida gravable & $\$ 17.500 .000$ \\
\hline$(=)$ & Tarifa 34\% & $\$ 5.950 .000$ \\
\hline$(-)$ & Retención en la fuente & $\$ 16.500 .000$ \\
\hline$(=)$ & Impuesto a cargo & $\$ 10.550 .000)$ \\
\hline
\end{tabular}

Fuente: elaboración propia.

10 Decreto 624 de 30 de marzo 1989, artículo 240. 


\section{Análisis comparativo de casos}

Una vez planteados los supuestos fácticos, se pudo realizar un análisis comparativo que se presenta a continuación.

\section{RÉGIMEN LEGAL APLICABle AL PERSONAL QUE EJECUTA EL CONTRATO}

En primer lugar, puede observarse que en lo que respecta al régimen legal de cada persona natural participante en el desarrollo del contrato, se encuentra una gran similitud, pues tanto afiliados partícipes como contratistas se rigen por una relación legal donde no hay subordinación y el aporte a Sistema General de Seguridad Social se hace bajo la figura de trabajador independiente, donde finalmente se aporta conforme al mismo IBC y la tarifa es igual para salud y pensión.

La naturaleza del contrato sindical, como se explicó en la sección I, resulta ser colectiva laboral, con una preponderancia civil, un modelo contractual único en el universo jurídico que reúne varios individuos, quienes prestan servicios a favor de un tercero. Bajo una correcta ejecución, los afiliados partícipes nunca pierden su calidad de independientes frente a la persona jurídica sindicato y frente al tercero, por ello podría denominárseles independientes agremiados.

Debido a esta naturaleza, las normas propias aplicables a sus afiliados partícipes son las de independientes lo que, para estos efectos, los equipara a los conocidos independientes que operan como contratistas. Debe indicarse que las normas laborales no estipulan un tratamiento diferencial en la proporción de los aportes frente a los afiliados partícipes, por ello, dada la naturaleza de la relación sindicato-afiliado y contratante-sindicato, se da aplicación a la normatividad sobre independientes.

No obstante, es importante indicar que, en virtud de la ya reiterada libertad sindical, en algunos sindicatos, en el reglamento del contrato sindical, se estipulan ciertas deducciones con un objetivo de provisión, como es el caso de los mencionados beneficios mensuales, anuales y semestrales, que se equiparan a aquellos de naturaleza laboral.

Ahora bien, en lo que respecta al tratamiento tributario de las personas naturales, es importante identificar que tanto afiliados partícipes (sindicato) como contratistas (sociedad) reciben similar tratamiento, sin embargo, podría llegar a modificarse tal pago si en el sindicato estos desembolsos se hicieran bajo otro concepto que variara la tarifa de retención, es decir, si a través del reglamento del contrato sindical se le diera otra connotación al pago (comisión, honorarios o salario).

En conclusión, frente a la normatividad aplicable al sujeto que ejecuta el contrato, tenemos que no existe mayor diferencia.

\section{RETENCIÓN EN LA FUENTE}

En los casos planteados, tanto sindicatos como sociedades comerciales reciben ingresos provenientes de contratos con similares condiciones, sin embargo, producto del régimen 
tributario aplicable, encontramos que las sociedades comerciales soportan una retención del $11 \%$ sobre el valor cancelado por el contrato, dicha retención no es aplicable al sindicato por su condición de no contribuyente.

Por otro lado, al realizarse los pagos a los prestadores del servicio, tanto en la sociedad comercial como en el sindicato se aplica una retención en la fuente similar, dicha condición podría variar en el caso de los sindicatos si en el reglamento del contrato sindical se indicara que todos los ingresos o una proporción de estos se reciben a un título diferente a honorarios. Esta situación ha sido tratada por la DIAN en los conceptos 30490 de 2012 y 76999 de 2011, donde reconoció que la "retención en la fuente y la tarifa aplicables por la compensación que reciben los trabajadores partícipes de un contrato sindical, dependerán del concepto en que sean percibidos de conformidad a lo que establezca el Reglamento del Contrato Sindical". Tal consideración fue expuesta en el primer apartado del presente trabajo.

\section{a. Caso I vs. caso II}

\section{Sindicato}

- SALUD X sindicato de gremio no soporta retención en la fuente por su calidad de no contribuyente.

- SALUD X sindicato de gremio realiza retención en la fuente a sus afiliados partícipes por un valor individual de $\$ 56.000$.

- Sociedad comercial

- SALUD Y SAS soporta la retención en la fuente por el valor recibido del contrato 001 a una tarifa del $11 \%$, es decir, la suma 16’000.000.

- SALUD Y SAS aplica retención en la fuente a sus contratistas por un valor individual de $\$ 56.000$.

En este punto encontramos una gran diferencia, pues la calidad de declarante no contribuyente del sindicato evita que a este se le retenga, situación que, si ocurre en la sociedad comercial, este aspecto repercute claramente en el flujo de caja como se explicará más adelante.

En lo que respecta al tratamiento de las personas naturales, tanto contratistas (sociedad) como afiliados partícipes (sindicatos) reciben la misma retención y no se presenta diferencia.

\section{IMPUESTO DE RENTA}

La carga tributaria correspondiente a este tributo denota una diferencia significativa, ya que nos encontramos ante una entidad catalogada como declarante no contribuyente, lo que indica que no realiza pago alguno por concepto de renta, en contraposición 
El principio de equidad tributaria en el tratamiento diferencial en el impuesto de renta entre sindicatos y sociedades 27

vinculamos una sociedad comercial perteneciente al régimen ordinario tributario, quien tributa a una tarifa plena del $34 \%$.

Para comparar este aspecto es necesario tener en cuenta la naturaleza de la persona jurídica, ya que el denominado no contribuyente resulta ser una entidad sin ánimo de lucro con la obligación operacional de reinvertir los excedentes, mientras que el régimen tributario ordinario posee ánimo de lucro y, por ende, la capacidad de repartir utilidades.

a. Caso I vs. caso II

\section{Sindicato}

- SALUD X, sindicato de gremio, realiza declaración, pero no realiza pago por concepto de impuesto de renta.

\section{Sociedad comercial}

- SALUD Y SAS tributa a una tarifa del $34 \%$. Para el caso en concreto tiene un saldo a favor de $\$ 10.550 .000$, producto de la retención practicada con anterioridad, debe indicarse que en este caso no se considera la renta presuntiva.

\section{Flujo de CAJA}

El flujo de caja indica la disponibilidad de recursos líquidos que posee un ente. En lo que respecta a este factor, existe una amplia diferencia entre los casos I y II y entre los casos III y IV, las razones son atribuibles con claridad a la retención en la fuente y al pago del impuesto sobre la renta, obligaciones que deben ser canceladas con anterioridad a la declaración.

\section{a. Caso I vs. caso II}

\section{Sindicato}

- SALUD X sindicato de gremio presenta un excedente neto de $\$ 17^{\prime} 500.000$

\section{Sociedad comercial}

- SALUD Y SAS presenta un excedente neto de \$1000.000

\section{Beneficios SOCIALES}

Los sindicatos pueden establecer vía reglamento del contrato sindical, o incluso de manera estatutaria, un conjunto de conceptos a favor de sus afiliados partícipes. Dichos conceptos se asemejan a los beneficios que surgen con ocasión de un contrato de trabajo, es decir, 
que son similares a la prima de servicios, vacaciones, cesantía e intereses a la cesantía. Dada la independencia reglamentaria y estatutaria en las organizaciones sindicales, algunas de estas optan por establecer beneficios de tal naturaleza, donde prácticamente se instaura un nuevo costo atribuible al contrato sindical teniendo como beneficiarios efectivos los trabajadores independientes afiliados al sindicato.

En lo referente a este aspecto, es clara la diferencia que se presenta con respecto a las sociedades comerciales, pues en ellas no es común que se creen este tipo de beneficios, mientras que en un sindicato puede indicarse que tal costo es reinvertir en el objeto social, que sería la protección y el mejoramiento de las condiciones laborales de sus afiliados. La mencionada práctica invita a varios cuestionamientos sobre la naturaleza de dichos costos, o su figura puede verse como un reparto de utilidades o en sí constituye un abuso del derecho. Este tema será objeto de estudio en la siguiente sección.

\section{Análisis jurídico}

Una vez presentados los conceptos más relevantes para desarrollar el objeto de esta investigación, y propuestos unos casos teórico-prácticos que nos indicaron con precisión los principales aspectos en el tratamiento en renta de sociedades comerciales y sindicatos cuando realizan la misma actividad, se pasará a plantear los principales aspectos diferenciales, para ello se tendrán en cuenta las condiciones de cada ente, su objeto social, el ánimo de lucro y la naturaleza para así, posteriormente, entrar a considerar a través los juicios de proporcionalidad de la honorable Corte Constitucional si puede o no darse una vulneración al principio de equidad tributaria.

Entrando en materia, en el presente caso tenemos que revisar aspectos importantes referentes a los sindicatos y sociedades comerciales en ejercicio de una actividad, para ello he propuesto referirme de manera analítica a las condiciones legales, al objeto social, al ánimo de lucro y a la naturaleza.

En primer lugar, al evaluar los aspectos indicados de cada uno de estos entes podemos ver que, por un lado, están las sas como sociedades comerciales, reguladas en su mayoría por las leyes 1258 de 2008 y 222 de 1995, y el Código de Comercio, denotando claramente una condición de ánimo de lucro, pues desde lo enunciado en la Ley 1258 de $2008^{11}$ no existen sAs con un objeto civil, es decir que siempre serán consideradas como un ente netamente comercial, el cual tiene una obligación potencial de repartir utilidades, lo que implica su vocación e indica claramente la causa del contrato de sociedades.

En temas contractuales esta causa señala el móvil fundamental del negocio jurídico, un objetivo potencial de recibir un excedente por parte del socio, denominado dividendo, en pocas palabras, se es miembro de una sociedad porque se quiere recibir una utilidad.

En ese mismo contexto, las SAS pueden optar por construir un patrimonio fuerte, capitalizando o realizando inversión en bienes para la persona jurídica. Dada su naturaleza, las

Ley 1258 de 5 diciembre del 2008, artículo 3. 
sociedades poseen una denominada vocación de permanencia, aceptada por una parte de la doctrina. Esta sociedad comercial puede desarrollar su objeto social a través de la vinculación de contratistas o directamente de personal bajo una relación laboral; lo mismo, como es lógico, hará variar las condiciones de salud, pensión y de acreencias laborales; sin embargo, frente a este aspecto de vinculación, existe libertad en la persona jurídica.

Sin importar el tipo de vinculación, la sociedad comercial asume una obligación clara con el personal que contrata, prestación que se realiza en la mayoría de los casos de manera periódica e independiente de la utilidad percibida por la sociedad.

El elemento ánimo de lucro revela una clara intención de repartir utilidades, razón por la cual, la normatividad tributaria grava de manera uniforme todas las sociedades comerciales.

Ahora bien, los sindicatos, aunque poco conocidos por la realización de actividades comerciales, industriales, de prestación de servicios, o simplemente por acciones diferentes a la protección de los derechos de los trabajadores, son personas jurídicas que pueden estar conformadas por sujetos de diferentes condiciones, como pudo apreciarse en el apartado inicial. En los casos expuestos, se hizo alusión a los sindicatos de gremio, donde quedó claro que la asociación se hacía en virtud de un vínculo común: profesión u oficio, caso de los sindicatos de gremio conformado por abogados o profesionales de servicios de la salud.

La naturaleza de los sindicatos es netamente laboral, sin que se haga necesario que los individuos que hacen parte de la persona jurídica estén subordinados por alguien. La normatividad aplicable es la laboral, la cual regula gran parte de los aspectos de estas organizaciones, no obstante, el vínculo que rige la persona afiliada con la persona jurídica es una relación legal de afiliación. Bajo esta perspectiva, podríamos indicar que los afiliados a un sindicato tienen una condición de gestor y dueño similar a la que sucede en las cooperativas de trabajo asociado, donde hay una persona natural asociada de manera colectiva pero la misma conserva unos elementos de independencia, desarrollando el objeto social de la persona jurídica. Tales elementos de independencia se evidencian en el hecho de cotizar e identificarse como un trabajador independiente al Sistema General de Seguridad Social y, como es claro, no estar subordinado.

Bajo esta perspectiva encontramos que el marco legal que rige los sindicatos es híbrido, tomando elementos de naturaleza laboral y civil, apartándose de premisas que indiquen que su finalidad siempre es comercial.

Debido a las condiciones y naturaleza de cada ente, se puede identificar una diferencia en la libertad de asociación o ingreso; en primer lugar, en lo que respecta a las sociedades comerciales, estas pueden ser por cuotas sociales o acciones, donde las primeras poseen un acceso restringido por el denominado derecho de preferencia; de igual forma, el cambio de un socio implica reforma estatutaria en la mayoría de los casos, lo cual exige un quórum decisorio calificado que termina haciendo compleja la cesión del aporte. Por otro lado, las sociedades por acciones permiten en principio una libre negociación de sus acciones de acuerdo con el artículo 379 del Código de Comercio, sin embargo, dicha negociabilidad 
puede llegar a restringirse por el pacto de un derecho de preferencia o simplemente por la intención de no querer vender las acciones, en pocas palabras, en las sociedades comerciales es posible negar el acceso a un tercero.

Ahora bien, dicha situación es diferente en las organizaciones sindicales, porque estas no pueden negar el acceso de un tercero, aquí el vínculo de afiliación es la única razón para no permitir la afiliación de un individuo, es decir, si el sindicato incluye trabajadores de una determinada rama el acceso será únicamente para estos, lo anterior ocurre en ejercicio del denominado derecho de asociación sindical, no obstante, este tipo de organización es más flexible en temas de acceso, pues no se necesita adquirir una cuota o acción, y, por lo general, existe una reiterada libertad de afiliación. Lo mismo se puede deducir de lo establecido en el Convenio 87 de la oIT cuando indica: "Los trabajadores y los empleadores, sin ninguna distinción y sin autorización previa, tienen el derecho de constituir las organizaciones que estimen convenientes, así como el de afiliarse a estas organizaciones, con la sola condición de observar los estatutos de las mismas"12.

Por otro lado, al analizar el ánimo de lucro de los entes sindicales, podemos ver que según la postura adoptada por la Corte Constitucional en Sentencia C-767 de 2000 referente a la capacidad para desarrollar actividades comerciales e industriales, se dejó claro que estos entes sí podían realizarlas, pero no podían ser actividades principales o únicas, tal postura indica que la capacidad de estos entes puede ser muy amplia y, a su vez, invita a cuestionarnos sobre la existencia del ánimo de lucro.

Este cuestionamiento se plantea teniendo en cuenta lo considerado como ánimo de lucro. En primer lugar, se sabe que el ánimo de lucro implica la realización de una actividad comercial o lucrativa, sin embargo, por sí solo no es un elemento definitivo para predicarlo en materia tributaria, a ello habría que añadirle el hecho de repartir utilidades y no reinvertir excedentes. Indicado este concepto, deberíamos preguntarnos: ¿el denominado sistema de compensaciones establecido en el reglamento del contrato sindical, conforme al cual se cancelan las obligaciones derivadas del cumplimiento del contrato, entre ellas las del servicio del personal participante, implica un reparto de utilidades?

Si recordamos lo indicado en la sección I, entenderemos que, de acuerdo con la naturaleza del contrato sindical, se requiere un reglamento para organizar los aspectos más importantes de los ingresos por recibir, entre ellos el pago de cada afiliado partícipe, dicho aspecto lo llamamos sistema de compensaciones. A través de este formalismo se determina cómo se pagará el servicio individual que, en conjunto, llevó a la ejecución y cumplimiento de las obligaciones contraídas, es decir, implica valorar por horas o metas un trabajo personal.

Dentro de ese marco tenemos un pago recibido por la persona jurídica-sindicato a razón de un servicio prestado, pago que se reparte de acuerdo con lo reglado. En este especial punto es donde quisiera detenerme, pues el reglamento indica una forma de pago a 
sus participantes que también podrían considerarse dueños, tal característica podría llevar a pensar que es un reparto de utilidades.

Otro aspecto por evaluar son los ingresos recibidos por los afiliados partícipes bajo la denominación de beneficios o bonos sindicales. Como se señaló en apartados anteriores, en el ejercicio de la libertad sindical y las facultades otorgadas por el Decreto 1429 de 2010 , los sindicatos pueden reglar diversos aspectos para disponer del dinero recibido con ocasión de un contrato sindical, cumpliendo mínimamente con los considerados como obligatorios. En los opcionales se encuentran los beneficios sociales y bonos sindicales, emolumentos que pueden ser pagados a los afiliados y se asemejan a la prima de servicios, vacaciones, cesantías e intereses a la cesantía, o pueden obedecer a un bono pagado en ocasión de un servicio, considerándose un pago en especie de acuerdo con la normatividad laboral.

Ahora bien, entrando a analizar dicho cuestionamiento, debe tenerse en cuenta que la naturaleza del negocio jurídico estudiado-contrato sindical requiere unos costos que son necesarios para su ejecución, siendo la compensación una contraprestación directa al trabajo ejecutado por el afiliado partícipe, quien depende necesariamente del pago del contrato. Dicha situación nos lleva a pensar en un contrato de prestación de servicios prestado por una persona jurídica conformada por trabajadores independientes, donde la misma no constituye un excedente, sino un costo natural atribuible al desarrollo del objeto social del sindicato. Sin embargo, la consideración expuesta presenta ciertas dudas, cuando al interior de las organizaciones sindicales los afiliados partícipes valoran de manera excesiva el trabajo de uno o varios afiliados, es decir, se indica en el reglamento que el valor remunerado a un afiliado es casi todo el ingreso proveniente del contrato sindical, situación que podría ser cuestionable, pues es cierto que en los sindicatos, dada su libertad, los afiliados pueden entrar a reglamentar a su gusto los contratos sindicales, indicando cómo se reparten los recursos sin tener lineamiento alguno. Para el caso I, si se indicara en los reglamentos que dichos excedentes irían destinados a uno o varios afiliados por partes iguales, ¿aún podríamos considerarlo como un costo atribuible al contrato sindical?, ¿se estaría reinvirtiendo en el objeto social del sindicato?, ¿podría verse como reparto de utilidades?

Por otro lado, en lo que respecta a los beneficios o bonos sindicales, podríamos entrar a considerar dos aspectos, en primer lugar, al hablar de beneficios sociales, muchos de estos se encuentran presupuestados en el pago recibido por la ejecución de un contrato (es decir, se pagan directamente del contrato) o, en algunos casos, se deducen directamente de la compensación por pagar al afiliado, sirviendo una provisión que equipara los derechos de los independientes a los empleados bajo una relación laboral. En pocas palabras, cumple una función de brindar a un independiente las mismas garantías que recibe un empleado, y esto se traduce en el ánimo de justicia que buscan los sindicatos.

Con respecto a los bonos sindicales, estos son acordados en los estatutos de la persona jurídica o reglamento del contrato sindical, y constituyen un derecho a favor de los afiliados partícipes, quienes en algunos casos reciben el ingreso en efectivo o en especie. Por ejemplo, es normal que al interior de los sindicatos se acuerde la entrega de un bono 
sindical redimible en mercado para el afiliado partícipe o para apoyar la compra de vivienda de un afiliado.

Considerando estos pagos, podría indicarse que al estar estipulados en los estatutos o el reglamento del contrato sindical, podrían verse como un pasivo para la persona jurídica, lo que nos lleva a tomarlos como un costo atribuible al contrato y no un reparto de utilidades o excedentes. El cuestionamiento surge una vez se observa la amplia libertad de dichos entes, pues prácticamente los afiliados partícipes pueden entrar a disponer de esta forma de todos los recursos adquiridos, dándoles una calificación de costo atribuible al contrato sindical o al ejercicio operacional.

Expuesto lo anterior se considera que, en principio, no existen elementos de juicio suficientes para considerar que los distintos pagos hechos a los afiliados partícipes de un sindicato puedan ser vistos como dividendos o reparto de excedentes, pues estos resultan ser una contraprestación, en algunos casos lógica y necesaria, por el trabajo desempeñado, o, lo que es igual, un costo atribuible al desarrollo del contrato. Ahora bien, debe tenerse en cuenta que el trabajo de los afiliados partícipes no constituye una labor administrativa, por tanto, no encuentra un límite en su costo. No obstante, quedan algunas dudas cuando en el reglamento o estatuto de los sindicatos se califican diversos costos, pues la amplia libertad en la constitución y el desarrollo de un sindicato permitiría creer que en diversas operaciones lo que se está persiguiendo es una intención de trasladar, bajo cualquier premisa, dineros a los afiliados calificándolos de costos atribuibles al contrato sindical.

Continuando con el análisis de los elementos propuestos, quisiera detenerme en el objeto social de estos entes jurídicos. Es claro que el objeto social de una persona jurídica indica su capacidad, es decir, la especial condición de contraer obligaciones y tener derechos, lo cual se lleva a cabo a través de las actividades que desarrolla.

Al revisar los casos analizados en la sección anterior, tenemos claro que el objeto social, tanto de las sas como de los sindicatos de gremio, era igual, esto es, la prestación de servicios jurídicos o de salud. Entendida esta igualdad, es lógico que las dos personas jurídicas coexisten en un mismo mercado, en pocas palabras, son claramente competencia.

De conformidad con esta última apreciación, tenemos dos vehículos jurídicos con los que podríamos abordar el mercado y prestar servicios, sin embargo, los dos poseen tratamientos tributarios diferentes, como se expuso en el análisis de casos comparativos de la sección II. En consecuencia, es necesario entrar a evaluar si la presente situación podría afectar la libre competencia, también conocida en el orden jurisprudencial y constitucional como libertad de empresa o libertad de iniciativa privada.

Al respecto la Corte Constitucional, en Sentencia C-183 de 1998, expuso:

Particularmente, el ejercicio de la potestad tributaria, que debe atender fines de interés general, no puede ser utilizado con el objeto deliberado de crear situaciones de ventaja privada en un mercado determinado. De una parte, la lucha entre los empresarios debe desenvolverse en la arena económica y llevarse a cabo buscando mejoras 
permanentes en la eficiencia. Su traslado al escenario político, en pos de la obtención de privilegios fiscales que se nieguen a sus respectivos competidores, le resta legitimidad tanto a la legislación tributaria como al sistema de empresa privada. Igualmente, convertir el poder tributario en factor de concesión selectivo de mayores o mejores márgenes de ganancia, para favorecer o perjudicar a ciertos empresarios, representa una mayúscula desviación del más grande poder de que dispone el Estado para perseguir la satisfacción de los intereses generales.

Esta consideración jurisprudencial señala la responsabilidad legislativa que en materia tributaria tiene el órgano que detenta el poder, lo que indica que debe crear normas de interés general y abstenerse de establecer ventajas injustificadas entre privados, pues esto afecta la libre competencia, y resulta ser una injerencia en la arena económica que debería premiar a sujetos con mejores bienes y servicios, no a través de beneficios fiscales.

Planteado lo anterior, ¿es posible que el tratamiento diferencial en renta propuesto sea una vulneración a la libertad económica? Este interrogante nos invita a ver con detenimiento el comportamiento económico de cada ente, valiéndonos de los casos planteados, donde encontramos que existía una gran diferencia cuando evaluamos aspectos concernientes al impuesto de renta, retención en la fuente y flujo de caja.

Con respecto a las sas veíamos cómo tenían un problema de liquidez, pues si bien se producía un saldo a favor en materia de renta, producto de la retención previa y las deducciones necesarias, debían acudir a un procedimiento de devolución de saldo a favor o imputar dichas sumas en declaraciones posteriores. De igual forma veíamos que, debido a su condición de sujeto pasivo, la retención en la fuente se aplicaba plenamente y terminaban siendo contribuyentes del impuesto de renta. Por otro lado, los sindicatos no tenían impuesto a cargo y, por su condición de no contribuyentes declarantes, no se les aplicaba la retención, teniendo más liquidez.

Las anteriores circunstancias llevan a considerar que las S.A.S. tienen una situación más desventajosa frente a los sindicatos de gremio cuando prestan los mismos servicios. El comportamiento en materia tributaria es un factor que claramente influye en la productividad y viabilidad de una empresa.

Al respecto la Corte Constitucional, en Sentencia C-183 de 1998, indicó que:

Las leyes tributarias suelen tener efectos variados en los precios relativos de los bienes y servicios que se ofrecen y demandan en los mercados. Empero, supera este efecto normal, la norma fiscal que, dentro de un determinado mercado, grava el ingreso de un operador y, simultáneamente, deja de gravar sin razón válida aparente el mismo tipo de ingreso de su competidor, generando una ventaja que reduce notoriamente las posibilidades de emular en cantidad, calidad y precio, hasta el punto de que la intervención unilateral del Estado pueda objetivamente calificarse como arbitraria, inaceptable o no soportable. 
En resumidas cuentas, podría indicarse que este tratamiento diferencial en materia tributaria con respecto a la renta proporciona una gran ventaja a los sindicatos frente a las sociedades comerciales cuando desarrollan un mismo objeto social, situación que hace más conveniente el uso de sindicatos para la prestación de servicios y podría llevar a pensar de manera inicial en una vulneración a la libre competencia. Este juicio se emite de esta manera pues más adelante se analizará si existe o no una diferencia justificada.

\section{Análisis del principio de equidad tributaria}

Una vez concluidos todos los aspectos por revisar, se analiza la vulneración del principio de equidad tributaria conforme a los presupuestos de la honorable Corte Constitucional.

Como bien se ha descrito en la sección I, el principio de equidad tributaria es un claro límite al poder normativo del Estado, lo que indica un ingrediente fundamental cuando se legisla en materia tributaria, pues los efectos de la norma deben estar dirigidos a ser iguales en la medida en que las condiciones de los individuos sobre los que recae, sean también iguales. No obstante, dicho presupuesto de igualdad real puede utilizarse para cumplir un fin constitucional, creando situaciones divergentes a pesar de la similitud de condiciones. Este precepto buscará la denominada justicia fiscal.

Partiendo del anterior enunciado, la Corte ha considerado necesario hablar de test de proporcionalidad, que en la mayoría de las situaciones ayuda a ver con un enfoque preciso el caso en estudio y el problema jurídico que se plantea, para así deducir si se vulnera el mencionado principio. Estos test de proporcionalidad han sido considerados como leves, intermedios y fuertes, como se hizo alusión en la sección I.

De acuerdo con lo tratado, la primera situación por analizar es si existe una condición formal igual entre los sindicatos y las sAs cuando realizan actividades similares.

Bajo el régimen legal aplicable a cada persona jurídica encontramos que se presenta una disparidad de las normas, por un lado, las sAs encuentran su regulación en normas de naturaleza comercial, mientras que los sindicatos en normas laborales que, en algunos casos, podrían considerarse como civiles; de igual forma, en lo que respecta al tema tributario existe una gran diferencia. Esta especial asimetría nos lleva a considerar que no existe uniformidad frente a la norma.

Ahora bien, revisadas estas condiciones formales, debemos entrar a analizar si las actividades realizadas son completamente iguales, es decir, hablar de una igualdad frente a la actividad y los servicios realizados, y de la destinación y objeto de los excedentes resultantes de la operación de cada ente.

Como es claro, los servicios de las SAs son prestados a través de un conocido contrato de prestación de servicios, contrato que en el caso I es ejecutado por profesionales vinculados a la sociedad y que de forma clara son prestados a nombre de esta. El negocio jurídico en mención podría adquirir una condición comercial, pues, a pesar de ser civil posee un ánimo de lucro. 
De otro lado, los sindicatos prestan sus servicios a través del mencionado contrato sindical, el cual ha sido definido como una figura sui generis, que posee elementos colectivos, laborales y civiles. A este negocio jurídico se adiciona un convenio de ejecución celebrado entre el afiliado y la persona jurídica, lo que permite su participación en el contrato sindical. La naturaleza del mencionado convenio es civil, atada indiscutiblemente al contrato principal.

A pesar de la diferencia planteada sobre la forma contractual, ¿qué pasa con el servicio prestado?, frente al tercero se dan similares condiciones; las personas jurídicas se obligan de igual manera, sus vinculados (personas naturales) ejecutan el contrato, a través de una prestación personal del servicio y el objeto desarrollado es igual. Tales elementos llevan a pensar que se realiza una actividad, que frente al tercero resulta igual, pero tiende a variar al considerarse lo que pasa al interior de cada persona jurídica.

Según lo expuesto, la forma de relacionarse en el mercado no sería distinta, pues el tercero no asume responsabilidad por el pago de nómina del prestador del servicio; la condición del servicio sería igual, prestada por profesionales, y quien respondería de manera patrimonial sería, inicialmente, la persona jurídica.

De acuerdo con la discusión planteada, ¿podríamos hablar de igualdad en la actividad prestada? Al observar el comportamiento frente al tercero, que finalmente es quien recibe el servicio, se podría creer que es el mismo servicio. Dicha teoría invita a traer al presente análisis lo propuesto con respecto a la vulneración de la libertad de empresa o libre competencia.

A reglón seguido, es necesario identificar la destinación y el objeto de los excedentes resultantes de la operación de cada ente. Como pudimos apreciar, antes de entrar en el cuestionamiento del principio de equidad, consideremos un conjunto de aspectos relacionados con el objeto social, la naturaleza y el ánimo de lucro de los entes en cuestión; dichos juicios nos servirán a la hora de establecer la destinación y objeto de los ingresos.

En lo planteado apreciamos que en las sociedades comerciales (SAS) los excedentes de los ingresos percibidos resultaban siendo, potencialmente, un dividendo, pues son la razón de ser del contrato de sociedades. Esta situación revela un claro ánimo de lucro y lleva a afirmar que la destinación y el objeto de los excedentes de cada operación tiene como fin el socio.

A su vez, en referencia al tema de los sindicatos se explicó lo concerniente al sistema de compensaciones y la reglamentación del contrato sindical, haciendo un cuestionamiento sobre los pagos recibidos por los afiliados partícipes a razón de compensación, beneficio o bono sindical. De dicho juicio se concluye que lo mismo no implicaba un reparto de dividendos, pues estos egresos eran considerados costos atribuibles al contrato. De esta manera, los excedentes debían ser reinvertidos en su objeto social.

En virtud de lo mencionado, se puede establecer una amplia diferencia entre la destinación y el objeto de los excedentes, lo cual indica que realmente no se posee un mismo ánimo comercial. 
Reunidos todos los elementos necesarios para realizar un juicio de constitucionalidad a la luz del principio de equidad, procedo a entrar en dicho análisis.

En virtud de lo descrito en la parte teórica de esta investigación, según lo planteado por la Corte Constitucional en materia de test, debe observarse este caso a la luz del test intermedio, pues la presente situación indica que existen presupuestos fácticos muy parecidos, donde se realiza la misma actividad, pero se recibe un tratamiento diferente en materia del impuesto de renta; así mismo, podría verse en esta situación un indicio de inequidad, el cual debe ser justificado para que supere el examen de constitucionalidad.

Con ocasión de la investigación propuesta, se plantean dos tesis; una referida a la constitucionalidad a la luz del principio de equidad y otra a su inconstitucionalidad.

\section{Test de constitucionalidad}

Como bien se mencionó a lo largo de este escrito, el principio de equidad en materia tributaria busca equiparar cargas impositivas teniendo en cuenta la capacidad económica o contributiva del sujeto. A pesar de ello, este principio constitucional no busca una igualdad total, pues existen situaciones que ameritan tratamientos desiguales para alcanzar la igualdad real.

Llama la atención el conjunto de similitudes en las actividades realizadas por sindicatos y sociedades comerciales cuya diferencia en el tratamiento tributario es evidente; sin embargo, a pesar del mero indicio, es importante reflexionar acerca de la justificación del trato desigual, es decir, si existe un fin constitucionalmente plausible que defienda esta asimetría.

En primer lugar, se debe tener en cuenta la tan mencionada naturaleza de los sindicatos, pues este factor lleva a desarrollar diversas justificaciones para salvaguardar esta tesis. La naturaleza colectivo-laboral de los entes sindicales implica la reunión de individuos de diversos oficios, profesiones, empresas o ramas, cuyo objeto social no puede ser netamente comercial o industrial según lo comentado y expuesto en la presente investigación, es decir que su ánimo no podrá ser de lucro.

Como bien se expuso, la remuneración pagada a los afiliados partícipes no puede ser vista como un reparto de utilidades por ser un costo atribuible al desarrollo del contrato sindical; así mismo, los excedentes que poseen los entes sindicales son reinvertidos en el objeto social cuya finalidad puede ser la protección de los derechos de sus afiliados.

La anterior afirmación indica que, desde la razón de ser de estos entes, se encuentra la protección y defensa de los derechos de los trabajadores, más precisamente el derecho al trabajo y la libertad de oficio. Abandonar esta finalidad implicaría una desnaturalización de la figura sindical.

Si nos detenemos a analizar los presupuestos de la ley laboral que regulan los temas concernientes a los sindicatos, entenderemos que es la misma ley la que permite cumplir los presupuestos del sindicalismo, a través de organizaciones compuestas por sujetos de 
diferentes condiciones. Por ejemplo, conformar un sindicato con trabajadores de diversas profesiones, oficios o empresas, para prestar servicios, permite fomentar y promover el derecho al trabajo.

Ahora bien, revisar el contrato sindical nos lleva observar que su especial naturaleza fue creada para permitir que unos trabajadores dependientes o independientes asociados puedan prestar servicios. El hecho de no subordinarse entre ellos, ni de ser subordinados por terceros, refiere una independencia significativa donde el elemento predominante no es la fortaleza económica, sino la suma de individuos que, al asociarse, pueden tener la capacidad de ofrecer servicios.

Aunado a lo anterior, los sindicatos pueden ser vistos como una alternativa de empleo, ya que posibilitan que personas que no son empleadas por empresas o personas naturales puedan asociarse y acceder a una remuneración. Esta posibilidad de empleo cumple otros presupuestos constitucionales como la dignidad humana, el mínimo vital y la vida.

Desde este punto de vista, los sindicatos cumplen su labor de protección a los trabajadores, desarrollando incluso lo establecido en tratados internacionales como los de la OIT, y son un medio que permite la participación activa de las personas en diversos oficios. Este aspecto tiene gran relevancia en tiempos donde el desempleo y la informalidad son altos, y las condiciones de vinculación laboral no son suficientes ni apropiadas.

Volviendo al contrato sindical, se observó cómo se podían pactar beneficios y bonos sindicales, emolumentos que finalmente podían equiparar las condiciones de un independiente a un trabajador dependiente. Desde su naturaleza única, el contrato sindical podía equipararse a un contrato de prestación macro donde la persona jurídica no tiene un ánimo de lucro, sino se busca la remuneración de una labor desarrollada finalmente por personas naturales. Nótese que, si bien la persona jurídica no tributa según los presupuestos del régimen ordinario de renta, los afiliados partícipes sí lo hacen de acuerdo con el régimen de personas naturales.

Por otro lado, estas organizaciones sindicales escapan al control normativo de los costos porcentuales referidos a labores administrativas, pues los pagos a los afiliados partícipes, hechos de acuerdo con el sistema de compensaciones, no son costos administrativos, por ende, no se les podría aplicar esta limitación. Sumado a lo anterior, el legislador no ha indicado de manera expresa que la actividad sindical se deba someter al gravamen de la renta en similar proporción al de una sociedad comercial.

En resumidas cuentas, la presente postura está sustentada en diversos criterios: i) la falta de ánimo de lucro de estas entidades, que no reparten excedentes; ii) el hecho de ser organizaciones que se constituyen en defensa de los intereses de los individuos, cumpliendo fines constitucionales que ni el mismo Estado puede satisfacer; iii) son una alternativa laboral para las personas que no pueden acceder a empleo; iv) la falta de una norma explícita que indique que su actividad debe ser gravada como una sociedad comercial.

Teniendo en cuenta lo expuesto, la presente asimetría de tratamientos tributarios en renta tendría una justificación constitucional. 


\section{Conclusiones}

La legislación laboral permite un amplio desarrollo de la figura sindical, lo cual se refleja en los múltiples tipos de sindicatos referidos, situación que indica que los sindicatos trascienden aquella relación laboral entre trabajador y empleador, y pueden ser constituidos por individuos de diversas empresas, oficios o profesiones. En los casos referenciados en la sección II del presente artículo, se expuso la conformación de sindicatos de gremio quienes desarrollaban actividades de prestación de servicios médicos y jurídicos. Dicha capacidad encuentra sustento en lineamientos legales y de orden jurisprudencial como los analizados en la Sentencia C-767 de 2000. Los sindicatos poseen capacidad para prestar servicios de manera amplia, y, a su vez, pueden realizar actividades comerciales e industriales cuando estas no resultan ser el objeto social único o principal de la organización sindical. Situación que revela una amplia capacidad de estos entes para ser utilizados como un vehículo en el mercado.

Es importante mencionar que el contrato sindical es un negocio jurídico de naturaleza civil-colectivo laboral, figura sui generis en el universo del derecho, la cual es la principal forma jurídica con la que los sindicales se relacionan con terceros, dicho contrato es un instrumento que permite a los sindicatos prestar un servicio a un tercero a través de sus afiliados partícipes, conservando estos últimos una naturaleza de trabajador independiente asociado, es decir, trabajador no subordinado que desarrolla el objeto social del sindicato.

En el desarrollo de la presente actividad investigativa se señaló cómo el contrato sindical puede ser reglado a través del reglamento de dicho contrato, formación que permite establecer los afiliados que participarán en la prestación del servicio, su remuneración, los beneficios sindicales, el concepto por el cual se paga al afiliado, las horas de trabajo, entre otros aspectos.

Ahora bien, con respecto al tratamiento tributario en lo referente al impuesto de renta es claro que los sindicatos, independientemente de su clasificación, no son contribuyentes, situación que difiere totalmente del tratamiento dado a una sociedad comercial que es un contribuyente del régimen ordinario de renta.

En el análisis de casos propuesto se evidenciaron varias diferencias en el tratamiento del impuesto de renta. En lo que respecta a las personas jurídicas puede concluirse que en los sindicatos no hay pago a razón del tributo, no se les aplica retención en la fuente, por ello no se afecta el flujo de caja, y pueden disponer ampliamente de los recursos destinándolos a beneficios sindicales. Por otro lado, en las sociedades se es contribuyente de acuerdo con el régimen ordinario, se les aplica retención en la fuente sin excepción, lo que afecta el flujo de caja dado el saldo a favor, y se pierde la posibilidad de disponer de los recursos señalados como beneficios sindicales.

La referida diferencia también puede predicarse al considerar de manera independiente el personal que labora para un sindicato o para la sociedad. De los casos referidos puede apreciarse que si bien la retención en la fuente de persona natural es igual, la misma 
puede variar en el caso de los sindicatos, ya que estos, al entregar un recurso a un afiliado partícipe, poseen la libertad para nominar este pago en el reglamento del contrato sindical (compensación, honorarios, salario o comisión), lo cual variaría la tarifa de retención para la persona natural.

Al observar el abuso en materia tributaria pudo indicarse que la denominada cláusula tributaria antiabuso del régimen tributario especial no podría ser aplicada a las consideradas prácticas irregulares de los sindicatos, pues estos entes pertenecen al régimen de no contribuyentes en el impuesto de renta.

Sin embargo, la cláusula general antiabuso podría aplicarse, pero se daría únicamente con el objetivo de reclasificar operaciones donde se encuentre vinculado un sindicato, es decir, debe analizarse en el caso en concreto si se encuentra en algún supuesto del artículo 869 del ET.

En el presente estudio se plantearon argumentos encontrados donde la constitucionalidad del tratamiento diferencial en el impuesto de renta pudiera alcanzar justificación en el desarrollo de derechos fundamentales, como lo son el trabajo, la libertad de profesión, la libertad de asociación sindical, el mínimo vital e incluso la vida, pues permitir el desarrollo de actividades a través del contrato sindical es dar vía libre a la prestación de servicios de trabajadores que encuentran en la remuneración de su labor un sustento básico. Sin embargo, por otra parte, es claro que la libertad de esta figura sindical invita a diversos cuestionamientos basados principalmente en un abuso del derecho, pues se está desnaturalizando la finalidad del sindicalismo, para disfrazar intereses económicos y de ahorro fiscal o tributario. De igual forma, llama la atención la planteada vulneración al principio de la libre competencia, ya que al coexistir en un mismo mercado sociedad comercial y sindicato, se presenta un beneficio excesivo para este último, que termina por afectar el valor final del servicio o producto ofrecido.

De igual forma, llama la atención la similitud entre las cooperativas de trabajo asociado y los sindicatos de gremio, lo cual no se refleja en el tratamiento del impuesto de renta, pues una es contribuyente del régimen tributario especial y el otro un no contribuyente.

La situación planteada en la investigación nos invita a observar con una mirada crítica el futuro tributario de las organizaciones sindicales, pues en la actualidad ya se ven como un mecanismo de "planeación tributaria" que, según lo desarrollado, goza de una libertad excesiva a la hora de constituirse, desarrollar actividades de diversa naturaleza y de otorgar beneficios a sus afiliados partícipes, quienes finalmente diseñan a su antojo el sindicato. Para terminar, el problema jurídico planteado a lo largo de la investigación llevaría a pensar que, posiblemente, el legislador tributario tiene una mirada muy limitada de los sindicatos, desconociendo la amplia capacidad de estos entes para prestar servicios y desarrollar actividades comerciales e industriales, pues la normatividad y la misma jurisprudencia lo permiten; tal condición se constituye en un clara ventaja en materia tributaria que atentaría contra el principio de equidad tributaria. 


\section{Referencias}

Cerón Coral , J. y Camacho Ramírez ,A. (2015). Derecho colectivo del trabajo. Ibáñez.

González Charry, G. (1990). Derecho colectivo de trabajo (tomo I). Biblioteca Jurídica Dike.

Insignares Gómez, R., Marín Elizalde, M., Muñoz Martínez, G., Piza Rodríguez, J. R. y Zornoza Pérez, J. J. (2016). Curso de derecho fiscal. Universidad Externado de Colombia.

Jaramillo Díaz, J. C. (2016). Entidades sin ánimo de lucro. Legis.

López, A. (2014). Elementos de derecho del trabajo. Librería Ediciones del Profesional.

Parra Escobar, A. (2014). Planeación tributaria y organización empresarial. Legis.

Piza Julio, R. (2015). La obligación tributaria y sus fundamentos constitucionales. Universidad Externado de Colombia.

Piza Rodríguez, J. R., Insignares Gómez, R. y Sarmiento Pérez, P. (Eds.) (2015). El impuesto sobre la renta y complementarios. Universidad Externado de Colombia.

Real Academia Española (s. f.). Prueba. En Diccionario de la lengua española. RAE.

Segura Medina, J. D. y González, O. L. (2018). El principio de equidad tributaria en el tratamiento diferencial en impuesto de renta entre sindicatos y sociedades. Universidad Externado de Colombia.

\section{Normatividad}

Congreso de la República de Colombia (2017). Código Sustantivo del Trabajo de 20 de diciembre. http://www.secretariasenado.gov.co/senado/basedoc/codigo_sustantivo_trabajo.html

Congreso de la República de Colombia (1989). Decreto 624. Estatuto Tributario, 30 de marzo. http://www.alcaldiabogota.gov.co/sisjur/normas/Norma1.jsp?i=6533

Congreso de la República de Colombia (2008). Ley 1258 de 5 de diciembre. http://www. secretariasenado.gov.co/senado/basedoc/ley_1258_2008.html 
Congreso de la República de Colombia (2016). Ley 1819. Reforma Tributaria, 29 de diciembre. http://www.secretariasenado.gov.co/senado/basedoc/ley_1819_2016. html

Dirección de Impuestos y Aduanas Nacionales (DIAN) (2011). Concepto 76999 de 3 de octubre.

Dirección de Impuestos y Aduanas Nacionales (DIAN) (2012). Concepto 30490 de 5 de noviembre.

Dirección de Impuestos y Aduanas Nacionales (DIAN) (2010). Concepto 78258 de 25 de octubre.

Organización Internacional del Trabajo (огт). Convenio 87.

Organización Internacional del Trabajo (OIT). Convenio 98.

Organización Internacional del Trabajo (оIт). Convenio 14.

Organización Internacional del Trabajo (отт). Convenio 15.

Presidencia de la República de Colombia (1991). Constitución Política de Colombia. http://www.corteconstitucional.gov.co/inicio/Constitucion\%20politica \%20 de\%20Colombia.pdf

Presidencia de la República de Colombia (2010). Decreto 1429 de 28 de abril. http://www. alcaldiabogota.gov.co/sisjur/normas/Norma1.jsp?i=39430

Presidencia de la República de Colombia (2004). Decreto Reglamentario 4400 de 30 de diciembre. de:http://www.alcaldiabogota.gov.co/sisjur/normas/Norma1 .jsp?i=15581

Presidencia de la República de Colombia (1992). Decreto 1372 de 21 de agosto. http:// www.alcaldiabogota.gov.co/sisjur/normas/Norma1.jsp?i=7298

\section{Jurisprudencia}

Consejo de Estado. Sentencia 11001-03- 25-000- 2010-00240- 00(2019-10) (C.P. Luis Rafael Vergara Quintero; 6 de julio de 2015).

Corte Constitucional de Colombia. Sentencia C-797 de 2000 (M.P. Antonio Barrera Carbonell; 29 de junio). 
Corte Constitucional de Colombia. Sentencia T-457 de 2011 (M.P. Luis Ernesto Vargas Silva; 27 de mayo).

Corte Constitucional de Colombia. Sentencia C-183 de 1998 (M.P. Eduardo Cifuentes Muñoz; 6 de mayo).

Corte Constitucional de Colombia. Sentencia 7136 (M.P. Hugo Suescun Pujols; 13 de diciembre).

Corte Constitucional de Colombia. Sentencia C-221 de 1992.

Corte Constitucional de Colombia. Sentencia C-094 de 1993.

Corte Constitucional de Colombia. Sentencia C-010 de 1995.

Corte Constitucional de Colombia. Sentencia C-222 de 1995.

Corte Constitucional de Colombia. Sentencia C-489 de 1995.

Corte Constitucional de Colombia. Sentencia C-036 de 1996.

Corte Constitucional de Colombia. Sentencia C-393 de 1996.

Corte Constitucional de Colombia. Sentencia C-412 de 1996.

Corte Constitucional de Colombia. Sentencia C-296 de 1999.

Corte Constitucional de Colombia. Sentencia 215 de 1999.

Corte Constitucional de Colombia. Sentencia C-1376 de 2000.

Corte Constitucional de Colombia. Sentencia C-508 de 2006.

Corte Constitucional de Colombia. Sentencia C-861 de 2006.

Corte Constitucional de Colombia. Sentencia C-903 de 2011.

Corte Constitucional de Colombia. Sentencia C-822 de 2011.

Corte Constitucional de Colombia. Sentencia C-635 de 2011. 
Corte Constitucional de Colombia. Sentencia C-913 de 2011.

Corte Constitucional de Colombia. Sentencia C-397 de 2011.

Corte Constitucional de Colombia. Sentencia C-1021 de 2012.

Corte Constitucional de Colombia. Sentencia C-304 de 2012.

Corte Constitucional de Colombia. Sentencia C-197 de 2013.

Corte Constitucional de Colombia. Sentencia C-264 de 2013.

Corte Constitucional de Colombia. Sentencia C-249 de 2013.

Fecha de recepción: mayo 30 de 2020.

Aprobación par 1: octubre 18 de 2020.

Aprobación par 2: octubre 10 de 2020. 